\title{
Structural Management Paradigm in the Models of Network Organizations
}

\author{
Alexander Yudov \\ Institute of Engineering Sciences \\ Pskov State University \\ Pskov, Russia \\ pskovspi@yandex.ru \\ Iuliia Bruttan \\ Institute of Engineering Sciences \\ Pskov State University \\ Pskov, Russia \\ bruttan@mail.ru
}

\author{
Vadim Trofimov \\ Institute of Engineering Sciences \\ Pskov State University \\ Pskov, Russia \\ tvm6419@yandex.ru
}

Anton Verteshev

Institute of Engineering Sciences

Pskov State University

Pskov, Russia

a_verteshev@mail.ru

\author{
Dmitry Andreev \\ Institute of Engineering Sciences \\ Pskov State University \\ Pskov, Russia \\ dandreev60@mail.ru
}

\begin{abstract}
Development problem of network organizations' modelling methods is considered in this article. It is characterized with two fundamental directions that are the basis of the scientific approach. The authors offer one more aspect of modelling - taking into account the influence on the object's structure and the produced products of external messages that carry structural rules, $i$. e. the rules needed for similar objects modelling.
\end{abstract}

Keywords - database, knowledge base, management paradigm, modelling, network organization

\section{INTRODUCTION}

Developing and researching modelling potential for doing practical tasks of any organizations within society digitalization is rather significant. This kind of the modelling problem has some features $[1,2]$. To start with, the modern stage of modelling development is characterized with two main directions that are the basis of scientific approach to modelling.

Firstly, this is a traditional fundamental approach that is based on deep mathematical study of the object, the aim of which is to define object domain, initial and boundary conditions, to set a modelling scenario and to analyze its results. This scientific field is characterized by research papers of A.A. Samarsky [3] and other scientists including studies of optimal control theory by N. N. Krasovsky [4].
Secondly, this is a well-known user-driven approach (G. S. Pospelov's school). The model appears when a set of predeveloped standardized modules of the future model are used as the representation of the nonprogramming practitioner, as the representation in the situational dependence. This set gives the opportunity to develop automated procedures of constructing the finite mathematical model. In addition, special attention can be paid to N.N. Moiseyev's studies on tasks of system analysis [5]. All approaches have their advantages, but, in fact, do not cover all possible ways to organize modelling processes.

For instance, V.V. Ivanishev school [6] indicates the importance of comprehending internal essence of the program part of the model for every particular application, without which serious mistakes of modelling are possible, because the structure and principles of modelling programs are not accessible to the authors of the mathematic models.

The paper describes the approach's development as another aspect of modelling taking into account the influence of external prescriptions on the object's structure and on the products generated in it. These input messages can carry structural rules, i. e. the external rules strictly needed for modelling similar objects [7] [9]. 
Thus, it seems to be very important to develop a modelling method of network organizations' management process.

The paper describes the methodology of defining an organization as a network one. The article also examines how input messages that carry structural rules and solutions to management tasks of network organizations affect its structure and its products.

\section{THE NOTION OF NETWORK ORGANISATION MODEL}

Network organization stands out from others because it uses mostly input messages specifically for the arrangement of management that is connected with maintaining its internal structure, management, leading to provision of output product due to preassigned structure of skills, knowledge and relations.

It is possible to say that the organization can be completely regarded as network if there is a process of structuring its network interactions in the chain from the command (structuring) input message to the formation on its basis of the finite product of a predetermined structure. This external structuring is considered to be the management process although somewhat different from its generally accepted signal variant.

It can be written as the following model of a network organization using the case of a university. To avoid confusion, it is necessary to note that this is a model of the prescribed organization of the educational process. No optimization of this structure is possible simply due to its purpose. However, research on minimizing the costs of technical equipment supporting this structure and of communication channels is essential.

Assume that $S_{F S E S}$ is an integral prescription for the organization of the entire educational process in all universities throughout the country set by the federal state educational standards (FSES).

Then $S_{F S E S}=\bigcup_{n=1}^{N} S_{n_{-} E M A}$, i.e. the general standard contains its differentiation for the organization of training in $N$ educational programs at the level of education and methodics associations (EMA).

It follows that structure $S_{n}$ of the prescribed organization of the educational process in $n$ educational program is described with the expression modelling it, containing the foundations of specified generalized prescription:

$$
S_{n} \subseteq\left(\sum_{k=1}^{K} p_{k}^{n}, \sum_{k=1}^{K} T_{k}^{p^{n}}, \sum_{k=1}^{K} M_{k}^{p^{n}}\right),
$$

where:

$P_{k}-k$ is a discipline from $K$ disciplines provided for the study in $S_{n}$ structure of $n$ educational program;

$p^{n}-$ is an index for the constituent parts of the model in relation to each particular discipline $P$ of $n$ educational program;
$T_{k}$ - is semester time provided in each individual discipline $P$ of $n$ educational program for the study of $k$ discipline.

$M_{k}$-is the prescription for the study of $K$ disciplines in $n$ educational program ("private structure" task of mutual provision of the studied disciplines).

\section{INFORMATION AND INTELLIGENT DATABASES AS THE BASIS OF MANAGEMENT ARRANGEMENT}

Considering the term "structural (data) management", we point out that it is tautological in the information field because according to $\mathrm{N}$. Wiener information is management in terms of mathematical optimization. Therefore, as we take this term to underline the difference between this kind of management and signal (structural-operator) one, we regard it as structural management (management based on analyzing changes in data links) as it is given in scientific literature $[10,11]$.

First, it is necessary to clarify a few terms related to this technology of management. We assume the obvious fact that we need to define knowledge as data relation as it enables to understand an input message as "structuring signal of control”.

The authors in [10] aim to develop information processes structurally and determine that the term "data" includes the description of objects, their environment, phenomena, facts, whereas knowledge, in its general sense is a variable in time and context named characteristic of the relations between pieces of data.

According to this definition, structural management (management at the knowledge level) implies that two or more systems understand equally (and perceive in the same context) interrelated information given in a language that carries and transmits data and knowledge about the subject domain [12]. It is quite clear that the concept "knowledge" always expressed in the language of relations (predicates) is complex as it can be implemented in numerous ways and is always linked to the concept "data” [13].

These ideas are supported by G.S. and D.A. Pospelov [14] who were the first to suppose that it is possible to manage unimaginable objects using natural human language. It is quite clear that in modern terminology everything said above repeats and specifies this hypothesis, indicates the need to organize management based on using context-sensitive languages [15]. This is the required non-computable thing that is mentioned in the works $[16,17]$.

It is shown $[10,18]$ that the offered definition of knowledge as a data link structure that can be observed, studied and changed, leads to an engineering approach of work with knowledge, to systems "with management on structures”. This management, with some restrictions, is quite applicable in modern computers. In addition, this definition puts everything in order when we compare the terms "database" and "knowledge base" and, ultimately, enables to construct a non-signal paradigm of 
Environment. Technology. Resources. Rezekne, Latvia Proceedings of the $13^{\text {th }}$ International Scientific and Practical Conference. Volume 2, 194-198

management - a management paradigm which requires structural changes of the object carried by input messages.

At the logical level of representation (Fig. 1) the system which stores both data and knowledge understood as described above consists of a related database (DB) and a knowledge base (KB), which can be together named just as an information base and a tool (system) of its development and maintenance (IBMS). In [10] this construction is considered as a "template" for the relational construction of an intelligent system. This paper examines it only as "a half" of the system with its own structure, changing under the influence of external messages in a language close to natural. Let us consider this question.

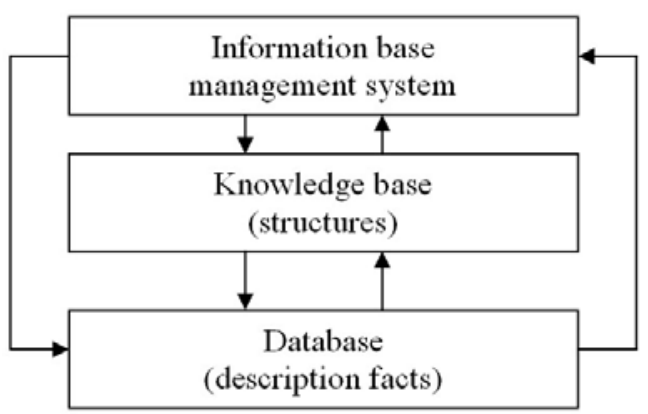

Fig. 1. Logical level of information base representation

One of the most successful approaches to representing a natural language saving its basic semantic constructions is the use of predicate constructions over it. The simplest thing here seems to replace full-length sentences of natural language with simple ones, which ideally consist of a subject, a predicate and an object. Theoretically it is possible only with a loss of the semantic part which is common for complex expressions. It is known [19] that for the simplest situations, partially formalized constructions with a limited thesaurus, such losses are negligible.

The above mentioned simple sentences are "templates" for constructing sentences of the predicate type, which have the form data-relation-data, i.e. completely appropriate for being written in the standard predicate form ARB. As shown in [19], verbs that represent relations are subject to the same formal logic as logical operators (the laws of commutativity, transitivity and others are executed with some special additions corresponding to the "internal logic of thinking in the terminology of this area”).

Consequently, in Fig. 1 we have not only a relational base, but also a construction that separately stores pieces of data and the relations between them, called knowledge. It hardly needs to be explained that it ensures the storage of the structure described by a set of data and relations, and if this is a description of an organization (for example, the relations of academic disciplines among themselves $M$, the names and content of academic subjects $P$, the correspondence of the academic discipline and hours of the corresponding lectures and practical lessons $T$ ), then this is a description not only of the organization itself, but of its current state.

From this description, that is an updated model at the core, one can make automatic selections and comparisons with standard prescriptions for organizing the structure of an organization (in our case, a university). It is possible to update the model continuously simply changing the links between pieces of data or entering new data based on the results of external messages analysis.

As given in a number of works [10, 20, 21, etc.], for the practical implementation of this update method of the database content, two-component construction shown in Fig. 2 is needed.

The given construction has the ability to store necessary information in relational (predicative) form pieces of data (including numeric and text) and the links between them. We assume (see Fig. 2) that Base 1 contains the last known variant of links. At the same time, Base 2 contains the same variant of data links through the same relations. After some time $\Delta \mathrm{t}$, Base 2 receives a new message about the desired new structure of links in connection with either a directive instruction about the change in the structure, or with a research of the possible consequences that occur after the introduction of a new structure.

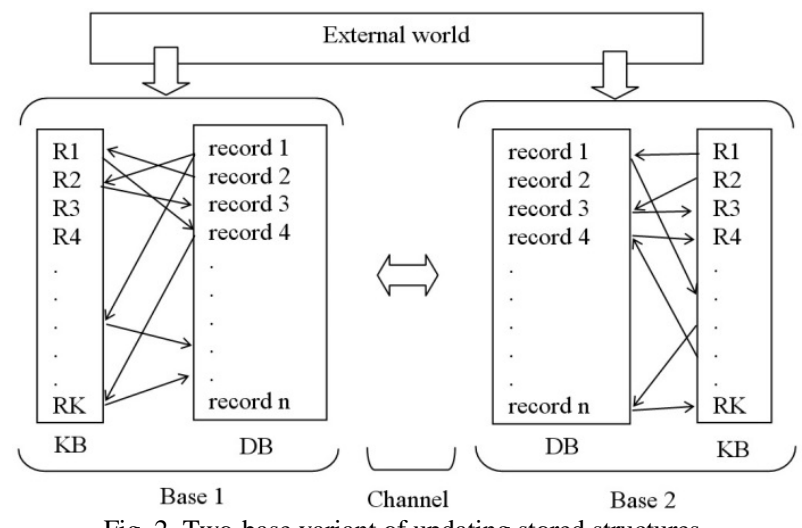

Fig. 2. Two-base variant of updating stored structures

In the latter case, it is also possible to organize the check of the failure consequences of some technical means (or the impossibility of conducting any discipline) for the entire situation connected with the preparation of the finite product. We have already had the criteria for such an assessment based on the changed structures of the object (the teaching process at the university).

In any case, the two-base construction saves the existing variant of the structure and makes it possible to assess the consequences of a disturbing situation without practical experiment.

For example, after making the plan of studies at university, it is possible to compare it with the 
requirements of the federal state educational standard (FSES) and other similar possibilities.

In case of purposeful work with data structures (providing the process with constant update of links due to subject-object communication or external messages), a base consisting of several information bases can be considered intelligent and controlling, generating a control message "from changing the structure" (Fig. 3) [10].

We can give the following comment about this system, i.e. the system of automatic communication. Terminologically, the "property of intelligence" of the system is synonymous with management and can be used only as a characteristic of the system complexity, as the requirement's indicator of precisely this kind of management. In addition, according to N. Wiener, "management is nothing more than sending messages that effectively influence the behavior of their recipient”.

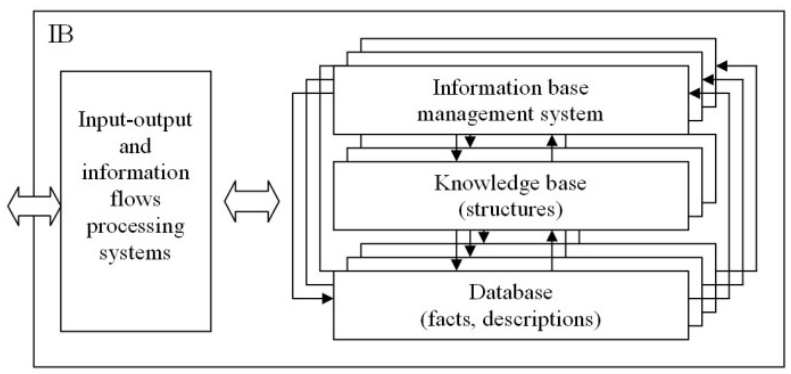

Fig. 3. Intelligent base as a set of information bases

Efficiency here means that we are initially talking about an active system of two-way interaction of these bases in Fig. 3. It can be considered that, the above given definitions in the aggregate, the information and even intelligent base receive their normal logical meaning the basis for the representation of time-dependent updating knowledge. Thus, the logical level shown in Fig. 1 of the information base representation is the main block for constructing a management system, consisting of numerous blocks that have different purposes and interact with different data flows. In the terminology of the network organization Fig. 3 reflects the process of changing the structure under the influence of external messages.

\section{STRUCTURAL MANAGEMENT PARADIGM}

The introduced term of an intelligent base as a part of interacting data and knowledge bases is constructive, because in this context a new management paradigm is constructed $[10,11]$.

The classical management paradigm ("signal" or "transfer" paradigm) comes from the concept of a control signal expressed in analog or digital form, control of the achieved management result and its correction for deviation by changing the transfer characteristics of the feedback control system [22, 23].

This kind of paradigm is natural and acceptable for systems which descriptive complexity allows their cybernetic representation or functional modelling. In this case, we assume that in a certain area of admissible control the transfer functions of the system have at least continuity, i.e. we assume that the concept of "control signal quantity" or "measurement" of a deviation in deviation range makes sense.

Saving this paradigm for system-complex objects automatically refers us to the level of their cybernetic model (a model that does not create an individual information image of a system with a variable structure of links). This modelling causes pointlessness of any attempts to organize management in high-level languages (not programming languages, but natural, context-sensitive languages), the transition to which, specifically for the purpose of managing public institutions (the universities belong to), was recommended in work [14].

The system view indicates $[10,11,24]$ that in order to resolve this contradiction, it is necessary to move to a different management paradigm. It comes from the concept of managing the changes in the links' structures of a certain system by changing the relations between pieces of data and the coordinating procedure of this structure between separate parts (object and subject) in an intelligent system. Consequently, it is proposed to name this paradigm the data paradigm of structures' coordination or the structural management paradigm.

Let us consider this question in details. Feedback, as a way to correct the subordinate function, does not exist in intelligent systems with "image accumulation" because of the absence of the evident subordinate function in its classical view. Its place is taken by the data structure and the apparatus for coordinating data structures. This process is not recursive and, perhaps, not even partially recursive [16].

A fundamentally important conclusion follows about other management mechanisms in system-complex situations (in particular, in the "network organizations" [25]) and about the limitation of modelling such situations not only by the inconsistency of the languages' description with the context-independent approach, but also by the management mechanism.

\section{CONCLUSION}

Thus, as it follows from the work [10], modelling "complex according to K. Boulding” object [24] with the help of even an intellectualized automatic control system, we admit that its observability is limited not only by the possibilities of its representation, but also by the fundamental replacement of the acceptance mechanism of management decisions. As it is known [26], in the theory of automatic control, observability is a dual concept of controllability if all its state variables can be directly or indirectly determined from the output (measured) vector of the system.

From a systemic point of view, observability is determined, first of all, by the system's language of representation, its communicative power. Observability 
Environment. Technology. Resources. Rezekne, Latvia Proceedings of the $13^{\text {th }}$ International Scientific and Practical Conference. Volume 2, 194-198

is maximum when the language is the system's own language, in situation when this language is adequately perceived by the observing system. In other cases, the system is observable with restrictions. The problem of stability of these systems is generally adequately considered only at the level of the homeokinetic plateau mechanism [10, 16, 27].

This work does not aim to use completely the new management paradigm for restructuring the network organization under external information flows. Today, the full implementation mechanism of such management is still extremely expensive to implement, and it is not needed in full under the realities of modern requirements for the arrangement of management at the level of the "educational doctrine" of federal state educational standards [28].

In compliance with the objectives of the research:

Work has been done to form the concept of a network organization as an organization in which the process of creating and transforming the internal structure of relations is required and carried out.

It is determined that network organization is an integral part of the external network that manages it and manufactures products reflecting the main content features of the components that form the structure of this network.

It is indicated that Pospelov's hypothesis about working with a textual representation of the organizational structure of an organization is necessary.

Conceptual models of the network organization are formed. They are focused on the representation of the university's technical means comparing their real structure and the structure required by the federal state educational standard.

\section{REFERENCES}

[1] V. N. Vasiliev, University management models based on information technologies. Petrozavodsk: Petrozavodsk State University, 2000. (in Russian)

[2] A. I. Yudov, "Modelling the structure of technical means of the educational process based on the concept of network organization," Proceedings of SPIIRAS, vol. 3, No. 1, pp. 206-210, 2002. (in Russian) [3] A. A. Samarsky, Introduction to the theory of differential schemes. Moscow: Nauka, 1971. (in Russian)

[4] N. N. Krasovsky, Theory of motion control. Moscow: Nauka, 1968. (in Russian)

[5] N. N. Moiseev, Mathematical tasks of system analysis. Moscow: Nauka, 1981. (in Russian)

[6] V. V. Ivanishchev, "Modeling without an intermediary," Izvestiya of the Russian Academy of Sciences. Theory and control systems, No. 5, pp. 27-32, 1997. (in Russian)

[7] D. A. Pospelov, Situational management: theory and practice. Moscow: Nauka, 1986. (in Russian)

[8] P. F. Drucker, Management Challenges for the 21st Century. New York: Harperbusiness, 1999.

[9] M. S. Charles, 5th generation management: integrating enterprises through human networking. [Bedford, Mass.]: Digital press, 1990.

[10] A. A. Erofeev and A. O. Polyakov, Intellectual control systems. St. Petersburg: SPbSTU, 1999. (in Russian)
[11] A. O. Polyakov, "System paradigm of control," Proceedings of St. Petersburg State Technical University: Computing, Automation, Radioelectronics, No. 472, pp. 32-49, 1998. (in Russian)

[12] I. Antonov, I. Bruttan, D. Andreev, and L. Motaylenko, "The method of automated building of domain ontology," in Environment. Technology. Resources: Proceedings of the 12th International Scientific and Practical Conference on Information Technologies, Rezekne, 2019, vol. II, pp. 34-37.

[13] D. Andreev, S. Lyokhin, L. Motaylenko, and S. Verteshev, "Models and algorithms for constructing a formalized description of production technologies," in Environment. Technology. Resources: Proceedings of the 12th International Scientific and Practical Conference on Information Technologies, Rezekne, 2019, vol. II, pp. 21-27.

[14] G. S. Pospelov and D. A. Pospelov, Influence of methods of the theory of artificial intelligence on the solution of traditional control problems. Moscow: Scientific Council on the complex problem "Cybernetics", 1977. (in Russian)

[15] D. Andreev, S. Lyokhin, V. Nikolaev, and O. Poletaeva, "Development of software for design ontological representations of production technologies," in Environment. Technology. Resources: Proceedings of the 12th International Scientific and Practical Conference on Information Technologies, Rezekne, 2019, vol. II, pp. 28-33.

[16] V. M. Lachinov and A. O. Polyakov, Informodynamics or the Path to the World of Open Systems. St. Petersburg: SPbSTU, 1999. (in Russian)

[17] R. Penrose, Shadows of the Mind. New York: Oxford University Press Inc., 1999.

[18] V. M. Nazaretov and D. P. Kim, Technical imitation of intelligence. Moscow: Higher School, 1986. (in Russian)

[19] G. A. Bulkin and A. O. Polyakov, Automated information-logical system in the language of predicates. In the book: "Dialogue and factual systems”. Moscow: Nedra, 1979. (in Russian)

[20] R. M. Yusupov et al., Telemedicine. New information technologies on the threshold of the XXI century. St. Petersburg: SPIIRAS, 1998. (in Russian)

[21] Reports of the scientific session MIFI-2000. Volume 3. Data banks, intelligent systems, MIFI, 2000. (in Russian)

[22] S. Verteshev, V. Konevtsov, "Processes control with fuzzy initial information in a complex of software design of digital control systems," in Environment. Technology. Resources: Proceedings of the 11th International Scientific and Practical Conference on Engineering sciences and production technologies, Rezekne, 2017, vol. III, pp. 332-336.

[23] S. Verteshev, V. Konevtsov, "Direct digital control in a complex of software design of digital control systems," in Environment. Technology. Resources: Proceedings of the 11th International Scientific and Practical Conference on Engineering sciences and production technologies, Rezekne, 2017, vol. III, pp. 337-342.

[24] K. Boulding, "General systems theory - the skeleton of science," Studies in general systems theory, Moscow, 1969, pp. 106-124. (in Russian)

[25] C. Shapiro and H. R. Varian, Information Rules: A Strategic Guide to the Network Economy. Boston: Harvard Business School Press, 1998.

[26] V. Konevtsov, I. Poletaev, S. Verteshev, "Discrete automatic schemes for ASC TP," in Environment. Technology. Resources: Proceedings of the 10th International Scientific and Practical Conference on Engineering sciences and production technologies, Rezekne, 2015, vol. I, pp. 67-71.

[27] J. van Guig, Applied general theory of systems. Moscow: Mir, 1981. (in Russian)

[28] A. I. Yudov, Organization of software and hardware of the university educational process. St. Petersburg: SPbSTU, 2002. (in Russian) 